\title{
Supply Hubs In Industrial Parks (SHIP): Research Perspectives
}

\author{
X. Qiu*, George Q. Huang, T. Qu \\ Department of Industrial and Manufacturing Systems Engineering \\ The University of Hong Kong \\ Pokfulam Road, Hong Kong \\ qiuxuan@hku.hk
}

\begin{abstract}
An industrial park is a cluster of enterprises located in one location to share common infrastructure, service and market opportunities. It has been adopted in many countries as an important tool for promoting the economic and industrial development. However, its further development has been impeded by the shortage of land resources especially for enterprises' construction of warehouses. The supply hub, having been employed by large suppliers to warehouse raw materials near manufacturers provides a promising way of solving such problem. In this paper, it is extended to "Supply Hub in Industrial Park (SHIP)" in the sense that warehouses of individual enterprises could be integrated into a single public warehouse and centrally serves the manufacturing processes of all the enterprises in an industrial park. Through the functioning of SHIP, it is expected that the land utilization and cost savings could be improved. As the initial study of SHIP, this paper focuses on several fundamental research perspectives: conceptual framework, working process, and potential benefits. Despite of the qualitative analysis, a mathematical model of SHIP is formulated. This work will contribute to the further research of logistics solutions in industrial parks.
\end{abstract}

Keywords-supply hub; industrial park; public warehouse

\section{INTRODUCTION}

An industrial park has been defined as a tract of land developed and subdivided into plots according to a comprehensive plan with provision for roads, transport and public utilities with or without build-up factories, for the use of a group of manufacturing enterprises [1] These enterprises share cost-effective infrastructure and communal services, and have more opportunities to cooperate with each other. Industrial parks have played an indispensable role in stimulating the economic and industrial development. It was estimated by UNEP (United Nations Environmenal Management) that there where approximately 20,000 industrial parks all over the world by 2001 [2]. Industrial parks can be categorized by different criteria. According to their locations, industrial parks can be classified as urban, semi-urban, and rural. With regard to the functions they perform, industrial parks are characterized as "composite parks", "ancillary parks", and "single trade parks". Concerning their sponsorships and ownerships, industrial parks are divided into governmental owned parks, privately financed parks, and privately assisted financed parks [1].
However, due to the rapid increase of production scales and land prices, the shortage of land resources for building warehouses in industrial parks is getting more serious. Difficulties of obtaining land have been regarded as the greatest barrier in the development of industrial parks [3]. Therefore, it's of great necessity to find suitable approaches for improving the land utilization in industrial parks. The supply hubs in industrial parks (SHIP) proposed in this paper aims to deal with this very problem.

Supply hubs have grown after the widespread implementation of Vendor Managed inventory (VMI). They were originally adopted by many electronic and computer manufacturers for storing raw materials and components offered by their suppliers to overcome the shrinking of production life cycle, so as to achieve cost reduction and improved responsiveness. However, the theoretical research of supply hubs is in arrear of their practice, and the related studies are rather limited. The supply hub was first defined by Zuckerman [4] as a location geographically close to a manufacturer's facility where all or some of its suppliers are warehoused with the agreement that the materials will be paid for only when consumed. Barnes et al. [5] presented an overview of the development of supply hubs. They pointed out the traditional arguments for and against using supply hubs, and they also provided some case examples of employing supply hubs. To our best knowledge, this is the first systematic study of supply hubs. Among the research of building operation models of supply hubs, Gaonkar and Visvanadham [6] formulated a collaborative scheduling model for supply hub management that schedules the production and delivery for manufacturer and its suppliers for optimal profit. Shah and Goh [7] provided a one supplier, one supply hub and one product model under deterministic conditions for demand to study the impact of operating policy parameters on supplier behavior. Later, two supply chain design models with and without supply hub were established for comparison of their total costs by $\mathrm{Li}$ et al. [8]. On the basis of the comparison results, $\mathrm{Li}$ et al. [9] built up models for supply chains with multiple supply hubs.

There are some limitations in the findings of this stream of research. First of all, the supply hub is defined as serving only one manufacturer. However, one supply hub using by multiple manufacturers hasn't been

\footnotetext{
* Corresponding Author
} 
considered. Moreover, the supply hub investigated above is only used to store raw materials or components from suppliers for one manufacturer. Whereas, researchers failed to study other potential important roles played by the supply hub in the supply chain. Albeit the advantages resulting from applying supply hubs have been mentioned in some papers, most of them were discussed from the asepct of geographical proximity to manufacturing facilities. There is a lack of analysis of benefits from various angles.

Our proposed SHIP is an extension of the concept of supply hub: SHIP is a public warehousing location in an industrial park where materials and products of all internal enterprises are centrally stored and managed. SHIP's substitution for individual warehouses of all enterprises in the industrial park will directly result in the reduction of land saving of their construction. Further, without private warehouses, manufacturers will save both inventory carrying costs and management costs. Therefore, the research in building supply hubs in industrial parks is of paramount significance for the development of industrial parks. The objective of this paper is to provide an overview of the SHIP from both qualitative and quantitative aspects. From the qualitative point of view, several fundamental research perspectives are presented, including background introduction, operation mode description, as well as benefits analyzation. From quantitative standpoint, mathematical models are developed without further numerical analysis.

The remainder of the paper is structured as follows. Section 2 proposes the basic principles of SHIP. In Section 3, two mathematical models are established. One is formulated based on the supply chain descibed in Section 2, while the other one is based on the traditional supply chain without the SHIP. Finally, conclusions and directions for future research are presented in Section 4.

\section{SUPPLY HUBS IN INDUSTRIAL PARKS}

(SHIP)

\section{A. Concept of SHIP}

Industrial parks can be characterirzed as a cluster of various manufacturing enterprises. Large enterprises often have their components or raw mateiral suppliers located in the same industrial park. It has been pointed out that the tightness of land resource is the largest bottleneck for the future development of industrial parks. New enterprises entering industrial parks require factory land space, and the continuing growth of current enterprises in industrial parks place increasing demand on additional space. However, those two kinds of demands can be hardly satisfied due to the limited and expensive land resource in industrial parks. In order to couple with these problems, the paper borrows the concept of supply hub to form the SHIP. A supply hub is geographically approximate to a specific manufacturer, used to store raw materials for it, while the SHIP is located in industrial parks, storing both materials and products for all the internal enterprises. The concept of supply hubs is extended to SHIP in two aspects: (1) Supply hub offers service to one specific manufacturer, while our proposed SHIP provides service to multiple manufacturers in the industrial park. (2) Supply hub is defined an intermediate point between suppliers and manufacturers, warehousing raw materials. Apart from storing materials for manufacturers, the SHIP also serves as the final product warehouse for those manufacturers. Additionally, the SHIP integrates all private warehouses of each company in the industrial park into a single public warehouse. Therefore, not only the land utilization could be increased, but also money spent on building and managing warehouses of the enterprises could be saved.

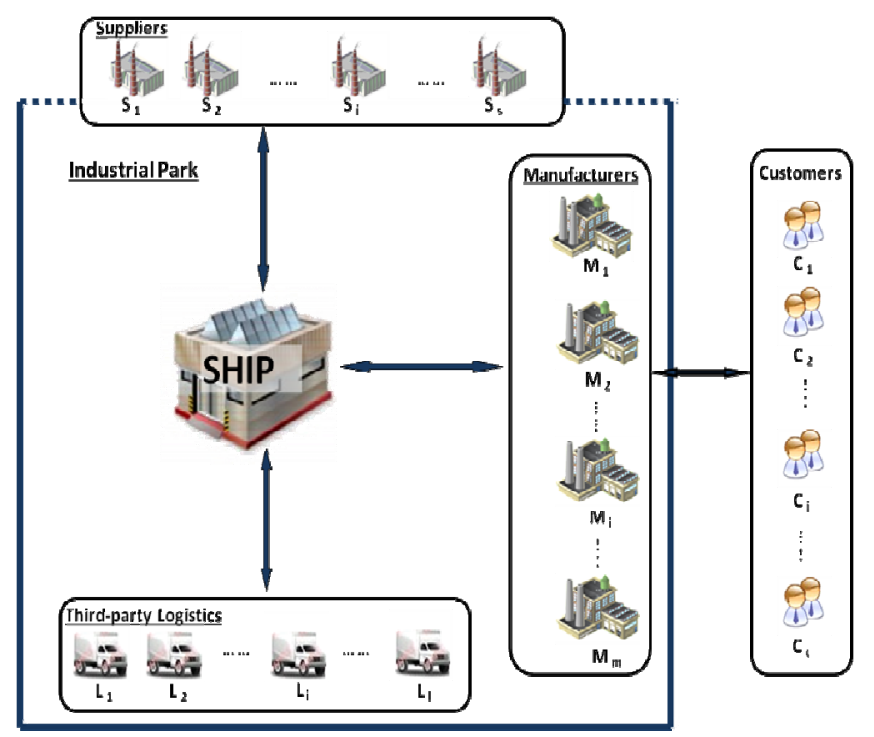

Figure 1. Schematic diagram of how SHIP works

The schematic diagram of how SHIP works is illustrated in Figure 1. An industrial park is typically comprised of four types of business entities: suppliers, manufacturers, a SHIP and third-party logistics companies. Suppliers serving for the internal manufacturers may locate inside or outside the industrial park, as indicated by the top part of Figure 1 . Similar to the operation mode of the original supply hub, the operation and management of SHIP are normally handed over to a third-party logistics provider. Besides, the outbound transportation from SHIP to customers and the inbound transportation from suppliers to SHIP are outsourced to another third-party logistics companies by the SHIP operator.

\section{B. Working process of SHIP}

The operation mode of SHIP is shown in Figure 2. To facilitate the decription of the flow process of the supply chain involving SHIP, we take a manufacturer $\mathrm{M}_{\mathrm{i}}$ for instance. The working process is triggered by the arrival of customers' order of finished products for $\mathrm{M}_{\mathrm{i}}$ (1.Order FP). The customers' order includes the type of product they want, the quantity, and the expected delivery timing. Given the production quantity, $\mathrm{M}_{\mathrm{i}}$ decides on the production schedule, and generates the purchase order of materials (2. POrder RM). According to the purchase order from $\mathrm{M}_{\mathrm{i}}$, the SHIP will set order to suppliers producing those materials (3. POrder RM). 
Simultaneously, the SHIP will set an order to 3PLs (4. DOrder RM), indicating the material types, quantity and the time of taking delivery of mateirals. At the designated time, 3PLs will ship the mateirals from suppliers to the SHIP (5. RM). Inside the SHIP, materials are received, transferred and put away into storage locations. To fulfill the demand of $\mathrm{M}_{\mathrm{i}}$, the SHIP will order 3PLs to transfer the required materials (6. DOrder RM). After being picked, sorted and packed, the orders will be shipped to $\mathrm{M}_{\mathrm{i}}(7$. RM). Having obtained the materials, $M_{i}$ proceed to the manufacturing process, producing to their predetermined production plans. Upon the completing of $\mathrm{M}_{\mathrm{i}}$ 's production process, SHIP will set an order to 3PLs (8. DOrder FP), and 3PLs will carry the finished products to SHIP (9. FP). Finally, according to the order (10. DOrder FP), 3PLs will take the responsibility of dispatching the required finished products to customers (11. FP). It is worth noting that instead of directly procuring raw materials from their suppliers, manufacturers should set their purchase orders to the SHIP. When some raw mateiral orders of manufanufacturers are the same, the SHIP will aggregate the common orders and purchase uniformly.

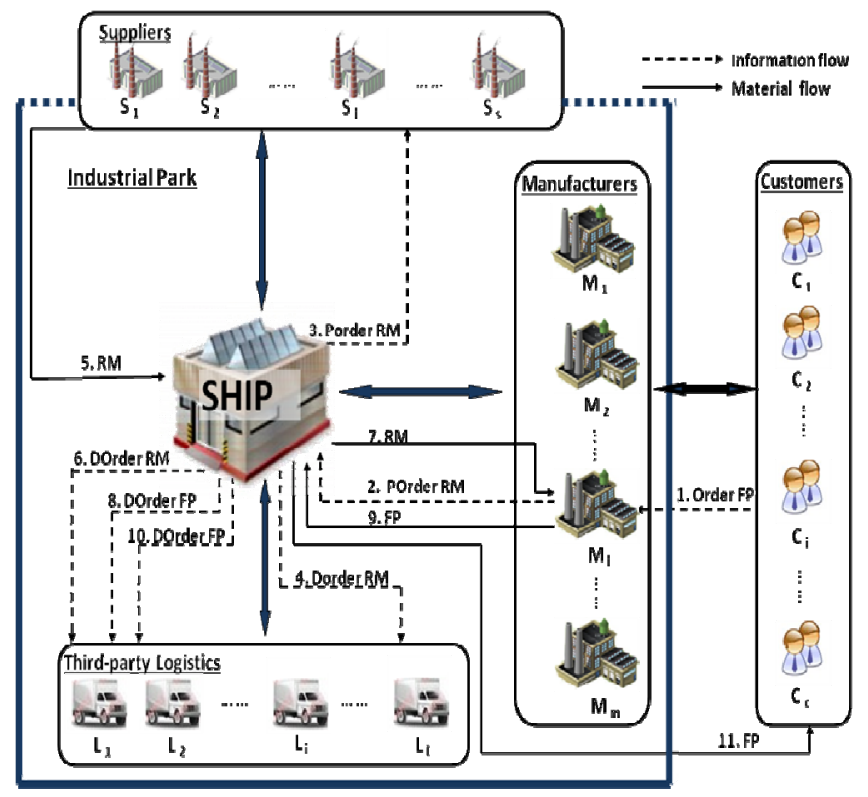

Figure 2. SHIP operation mode

\section{Benefits of SHIP}

Through the operation of SHIP described above, the following benefits could be achieved.

\section{1) Land resource economization}

Before the introduction of SHIP, all enterprises in industrial parks store products in their private warehouses. It has been pointed out that virtually every product in every industry in every country is seasonal, and most of the seasonal patterns are known and predictable [10]. Take the impact of weather for instance. The sale of air conditions is heavy in summer and light in winter, while the sale of warm air blower is the opposite. In the warehouse dealing with seasonal products, the utilization of space fluctuates throughout a year. In off-seasons, the warehouse will be idle and the space will be wasted. However, SHIP, through integrating all private warehouses of the companies in industrial parks into a single public warehosue, is capable of increasing the land utilization. By analyzing the seasonal pattern of every product in the industrial park, the SHIP operator could evaluate the dimensions of storage area, assuring that the utilization of space is maximized in every season. Obviously, the total amount of storage space of every company far outstrips that of the SHIP, and hence the land resource will be significantly saved.

\section{2) Cost saving}

By using SHIP, companies in the industrial park no longer have to spend expenses on building and operating warehouses, acquiring systems and equipments, and employing and training warehouse staff. All companies need is renting space in SHIP according to their demand, and the SHIP operator will offer professional and efficient service to them. Moreover, as described in the previous section, it is no longer need for the manufacturers to negotiate with suppliers about purchasing. The SHIP will take charge of the centralized procurement from suppliers. Therefore, not only the transaction costs resulting from the negotiation and cooperation will be sharply reduced, but also the larger purchase quantity will lower the procurement costs. Furthermore, the consolidation of multiple inventory locations into the single one will lead to the risk pooling effect. It is documented that risk pooling could reduce the need for safety stock and consequently decrease the inventory holding costs [11][12]. The substantial cost savings by the enterprises could be redirected to areas that gain a higher contribution to increasing profits such as research and development, manufacturing, employee education, etc.

\section{3) Economies of scale acquisition}

Considering the original freight transportation from suppliers to manufacturers in industrial parks, materials are often delivered through small load, especially to enterprises which purchase from multi-suppliers in small batches each time. The cost of delivery is excessively high for small shipments. However, as the SHIP is responsible for the distributions of all companies in industrial parks, different orders of the same manufacturers could be consolidated into a single load. It is known that the larger quantity dispatched on the same vehicle, the more per-unit transportation cost could be saved. Therefore, enterprises in industrial parks could take advantage of the transportation economies of scale.

\section{MATHEMATICAL MODEL}

\section{A. Notations}

Before presenting the model formulation, the following notations are defined.

Indices:

$\begin{array}{ll}t & \text { Index for period, } t=1,2,3, \ldots, T \\ r & \text { Index for raw materials, } r=1,2,3, \ldots, R \\ i & \text { Index for finished products, } i=1,2,3, \ldots, I \\ s & \text { Index for suppliers, } s=1,2,3, \ldots, S\end{array}$


$m \quad$ Index for manufacturers, $m=1,2,3, \ldots, M$

$K \quad$ SHIP identifier

Parameters:

$D_{i m t} \quad$ Demand of finished product $i$ at manufacturer $m$ during period $t$

$H_{r t} \quad$ Unit cost of holding raw material $r$ in SHIP during period $t$

$H_{i t} \quad$ Unit cost of holding finished product $i$ in SHIP during period $t$

$h_{r s t} \quad$ Unit cost of holding raw material $r$ in supplier $s$ during period $t$

$h_{i m t} \quad$ Unit cost of holding finished product $i$ in manufacturer $m$ during period $t$

$P_{r s t} \quad$ Unit cost of producing raw material $r$ in supplier $s$ during period $t$

$P_{i m t} \quad$ Unit cost of producing finished product $i$ in manufacturer $m$ during period $t$

$\mathrm{TC}_{r s t} \quad$ Unit transportation cost from supplier $s$ to

SHIP for raw material $r$ during period $t$

$\mathrm{TC}_{r m t}$ Unit transportation cost from SHIP to manufacturer $m$ for raw material $r$ during period $t$

$\mathrm{TC}_{i n t} \quad$ Unit transportation cost from manufacturer $m$ to SHIP for finished product $i$ during period $t$

$\mathrm{TC}_{r s m t} \quad$ Unit transportation cost from supplier $s$ to manufacturer $m$ during period $t$

$\mathrm{PC}_{r s t} \quad$ Unit price cost of raw material $r$ from supplier $s$ to SHIP during period $t$

$\mathrm{PC}_{r s m t} \quad$ Unit price cost of raw material $r$ from supplier $s$ to manufacturer $m$ during period $t$

$A_{r i} \quad$ Number of units of raw material $r$ used to make one unit of finished product $i$

$C_{r s t} \quad$ Production capacity for raw material $r$ offered by supplier $s$ during period $t$

$C_{i m t} \quad$ Production capacity for finished product $i$ offered by manufacturer $m$ during period $t$

$W_{r s t} \quad$ Transportation capacity for shipping raw material $r$ from supplier $s$ to SHIP during period $t$

$W_{c m t}$ Transportation capacity for shipping raw material $r$ from SHIP to manufacturer $m$ during period $t$

$W_{i m t} \quad$ Transportation capacity for shipping finished product $i$ from SHIP to manufacturer $m$ during period $t$

$W_{r s m t} \quad$ Transportation capacity for shipping raw material $r$ from supplier $s$ to manufacturer $m$ during period $t$

$B_{K} \quad$ Storage capacity at SHIP

$V \quad$ Volume of raw material $r$

$V_{i} \quad$ Volume of finished product $i$

Decision variables:

$\mathrm{Q}_{r s t} \quad$ Quantity of raw material $r$ produced in supplier $s$

$\mathrm{Q}_{i m t} \quad$ Quantity of finished product $i$ produced in manufacturer $m$ during period $t$

$S_{r s t} \quad$ Quantity of raw material $r$ transported from supplier $s$ to SHIP during period $t$

$S_{r m t} \quad$ Quantity of raw material $r$ transported from
SHIP to manufacturer $m$ during period $t$

$S_{i m t} \quad$ Quantity of finished product $i$ transported from manufacturer $m$ to SHIP during period $t$

$S_{r s m t} \quad$ Quantity of raw material $r$ transported from supplier $s$ to manufacturer $m$ during period $t$

$I N_{r t} \quad$ Inventory level of raw material $r$ in SHIP during period $t$

$I N_{i t} \quad$ Inventory level of finished product $i$ in SHIP during period $t$

$I_{r s t} \quad$ Inventory level of raw material $r$ in supplier $s$ during period $t$

$I_{i m t} \quad$ Inventory level of finished product $i$ in

manufacturer $m$ during period $t$

$I_{r m t} \quad$ Inventory level of raw material $r$ in

manufacturer $m$ during period $t$

$X_{i m t} \quad 1$ if finished product $i$ is produced by manufacturer $m$ during period $t ; 0$ otherwise.

$X_{r s t} \quad 1$ if raw material $r$ is produced by supplier $s$ during period $t ; 0$ otherwise.

$Y_{r m t} \quad 1$ if raw material $r$ is transported from SHIP to manufacturer $m$ during period $t$; 0 otherwise.

$Y_{r s m t} \quad 1$ if raw material $r$ is transported from supplier $s$ to manufacturer $m$ during period $t$; 0 otherwise.

\section{B. Model overview}

In this section, a production-distribution model is developed to quantify the proposed SHIP. For future comparison, a similar model is formulated without considering the SHIP in an industrial park. The first model includes a SHIP, multiple manufacturers, and suppliers both inside and outside the industrial park. Manufacturers may engage in different or similar industrial areas. Those specialize in similar areas often share some common suppliers. In each planning horizon, suppliers produce raw materials, which are then shipped to the SHIP. The SHIP will deliver the required raw materials to each manufacturer. After the reception of raw materials, manufacturers will perform operations to produce finished products. Finished or semi-finished products will again be delivered to SHIP and wait for dispatch to customers. While in the second model, there is no intermediation point between suppliers and manufacturers. Manufacturers purchase and receive raw materials directly from their suppliers. In formulating these two models, the objectives remain the same: to minimize the total cost including the production cost, procurement cost, transportation cost and inventory holding cost, while satisfying various constraints. The following assumptions are made:

(1) The planning horizon consists of $T$ discrete time periods;

(2) Demand for each finished product in each period is deterministic and constant;

(3) Transportation capacity is limited;

(4) The storage capacity at SHIP is limited;

(5) Distribution lead time is negligible;

(6) Backorders are not allowed. 


\section{Mathematical formulation}

1) Mathematical model with SHIP

The total cost of supply chain based on the SHIP is formulated as follows:

Min cost $=$

$$
\begin{aligned}
& {\left[\sum_{t=1}^{T} \sum_{s=1}^{S} \sum_{r=1}^{R}\left(P_{r s t} \cdot Q_{r s t} \cdot X_{r s t}\right)\right.} \\
& \left.+\sum_{t=1}^{T} \sum_{m=1}^{M} \sum_{i=1}^{I}\left(P_{i m t} \cdot Q_{i m t} \cdot X_{i m t}\right)\right] \\
& +\left\{\sum_{t=1}^{T} \sum_{s=1}^{S} \sum_{r=1}^{R}\left[\left(T C_{r s t}+P C_{r s t}\right) \cdot S_{r s t}\right]\right. \\
& +\sum_{t=1}^{T} \sum_{m=1}^{M} \sum_{r=1}^{R}\left[T C_{r m t} \cdot S_{r m t} \cdot Y_{r m t}\right] \\
& \left.+\sum_{t=1}^{T} \sum_{m=1}^{M} \sum_{i=1}^{I}\left(T C_{i m t} \cdot S_{i m t}\right)\right\} \\
& +\left[\sum_{t=1}^{T} \sum_{r=1}^{R}\left(H_{r t} \cdot I N_{r t}\right)\right. \\
& \left.+\sum_{t=1}^{T} \sum_{i=1}^{I}\left(H_{i t} \cdot I N_{i t}\right)\right]
\end{aligned}
$$

$$
\text { s.t. }
$$$$
Q_{r s t} \leq C_{r s t} \cdot X_{r s t}
$$$$
\forall r, s, t
$$$$
Q_{i m t} \leq C_{i m t} \cdot X_{i m t}
$$$$
\forall i, m, t
$$$$
\left[\begin{array}{l}
\sum_{i=1}^{I} V_{i}\left(I N_{i t}+\sum_{m=1}^{M} S_{i m t}\right) \\
+\sum_{r=1}^{R} V_{r}\left(I N_{r t}+\sum_{s=1}^{S} S_{r s t}\right)
\end{array}\right] \leq B_{K}
$$$$
\forall t
$$

$S_{r s t} \leq W_{r s t}$

$\forall r, s, t$

$S_{r m t} \leq W_{r m t} \cdot Y_{r m t}$

$S_{i m t} \leq W_{i m t}$

$\forall r, m, t$

$Q_{r s t}=S_{r s t}$

$\forall i, m, t$

$Q_{i m t}=S_{i m t}$

$\forall r, s, t$

$S_{r m t}=\sum_{i=1}^{I}\left(Q_{i m t} \cdot A_{r i}\right)$

$\forall i, m, t$

$\forall r, m, t$

$I N_{r, t-1}+\sum_{s=1}^{S} S_{r s t}=\sum_{m=1}^{M}\left(S_{r m t} \cdot Y_{r m t}\right)+I N_{r t} \quad \forall r, t$

$I N_{i, t-1}+\sum_{m=1}^{M} S_{i m t}=\sum_{m=1}^{M} D_{i m t}+I N_{i t}$

$\forall i, t$

$Q_{r s t}, Q_{i m t} S_{r s t}, S_{r m t}, S_{i m t}, I N_{r t}, I N_{i t} \geq 0$

$\forall i, r, m, s, t$

$X_{i m t}, X_{r s t}, Y_{r m t} \in\{0,1\}$

$\forall i, r, m, s, t$

The objective function is divided into seven components: (A1) the raw material production cost, (A2) the finished product production cost, (A3) the raw material purchase price and transportation cost from suppliers to the SHIP, (A4) the transportation cost from the SHIP to manufacturers, (A5) the transportation cost from manufacturers to the SHIP, (A6) the inventory holding cost of raw materials at the SHIP, and (A7) the inventory holding cost of finished product at the SHIP. Constraints (1) and (2) describe the production capacity constraint of suppliers and manufacturers. Constraint (3) is the capacity limitation of the SHIP. Constraints (4)-(6) are the transportation capacity restrictions. Constraint (7) and (8) guarantee the quantity delivered from suppliers or manufacturers are equal to their production quantity. Constraint (9) matches raw materials to the production requirements of manufacturers. Constraints (10) and (11) are the inventory balance constraints of raw materials and finished products at the SHIP. Constraint (12) imposes the non-negativity restriction on decision variables. Finally, constraint (13) restricts the binary variables.

\section{2) Mathematical model without SHIP}

The total cost of supply chain without considering SHIP is represented as follows:

Min cost $=$

$$
\begin{aligned}
& {\left[\sum_{t=1}^{T} \sum_{s=1}^{S} \sum_{r=1}^{R}\left(P_{r s t} \cdot Q_{r s t} \cdot X_{r s}\right)\right.} \\
& \left.+\sum_{t=1}^{T} \sum_{m=1}^{M} \sum_{i=1}^{I}\left(P_{i m t} \cdot Q_{i m t} \cdot X_{i m}\right)\right] \\
& +\sum_{t=1}^{T} \sum_{s=1}^{S} \sum_{m=1}^{M} \sum_{r=1}^{R}\left[\left(P C_{r s m t}+T C_{r s m t}\right) \cdot S_{r s m t} \cdot Y_{r s m t}\right] \\
& +\left[\sum_{t=1}^{T} \sum_{s=1}^{S} \sum_{r=1}^{R}\left(I_{r s t} \cdot h_{r s t}\right)\right. \\
& \left.+\sum_{t=1}^{T} \sum_{m=1}^{M} \sum_{i=1}^{I}\left(I_{i m t} \cdot h_{i m t}\right)\right]
\end{aligned}
$$

s.t.

(1), (2), (14), (15)

$S_{r s m t} \leq W_{r s m t} \cdot Y_{r s m t}$

$\forall r, m, s, t$

$\sum_{m=1}^{M}\left(S_{r s m t} \cdot Y_{r s m t}\right) \leq Q_{r s t}$

$\forall r, s, t$

$\sum^{S}\left(S_{-i} \cdot Y_{r, m}\right) \geq \sum^{I}\left(\mathrm{~A}_{i} \cdot Q_{m,}\right) \quad \forall r, m, t$

$Q_{i m t} \geq D_{i m t} \quad \forall i, m, t$

$I_{r s, t-1}+Q_{r s t}=\sum_{m=1}^{M}\left(S_{r s m t} \cdot Y_{r s m t}\right)+I_{r s t} \quad \forall r, s, t$

$I_{i m, t-1}+Q_{i m t}=D_{i m t}+I_{i m t} \quad \forall i, m, t$

$I_{r m, t-1}+\sum_{s=1}^{S}\left(S_{r s m t} \cdot Y_{r s m t}\right)=\sum_{i=1}^{I}\left(A_{r i} \cdot Q_{i m t}\right)+I_{r m} \forall r, m, t$

$S_{r s m t}, I_{r s t}, I_{i m t} \geq 0$

$\forall i, r, m, s, t$

$Y_{r s m t} \in\{0,1\}$

$\forall r, m, s, t$

The objective function includes the production cost of suppliers and manufacturers (B1) (B2), the transportation and purchase cost of raw materials from suppliers to manufacturers (B3), and the inventory holding cost of raw materials in suppliers (B4) and finished products in manufacturers (B5). The transportation capacity constraint is described by constraint (14). In constraint (15), the total quantity of the raw material shipped from a supplier to manufacturers cannot exceed the amount of that material produced in that supplier. Raw material 
requirements for production are represented by constraint (16). Constraint (17) ensures the production quantities of one product in a manufacturer satisfy the demand of that product. The inventory flow constraints are presented by constraints (18)-(20). Constraint (21) preserves the non-negativity restrictions on the decision variables while constraint (22) ensures the integrity restriction of binary variables.

\section{CONCLUSION}

In this paper, the SHIP is proposed as a promising approach to resolve the land scarcity problem for establishing warehouses in industrial parks. Several contributions are made in this paper. The definition of SHIP extended the supply hub to serving multiple manufacturers, and centrally storing and managing both materials and products of all internal enterprises. Besides, the operation mode of SHIP is described, and benefits of applying the SHIP are discussed from different aspects. Furthermore, two production and distribution models under deterministic conditions of demand are formulated respectively for the three echelon supply chain with SHIP, and a two echelon one without SHIP.

On the basis of the fundamental research perspectives investigated in this paper, future studies should be conducted on several aspects. Firstly, approaches should be sought to solve the two models we developed so as to compare the results. To approximate the realistic conditions, some restrictions of the model should be relaxed, such as considering the model under stochastic demand. Another extension would be to incorporate delivery earliness and tardiness costs in our model. To further exploit the benefits analyzed in section 2, new models should be formulated to quantify the benefit of risk pooling and centralized procurement resulting from the establishment of SHIP.

\section{REFERENCES}

[1] United Nations Industrial Development Organization (UNIDO), "Industrial Estate: Principles and Practices", Vienna, Australia: UNIDO, 1997.

[2] C. Francis and S. Erkman, "Environmental Management for Industrial Estates: Information and Training Resources", Paris, France: United Nations Environmental Program, Division of Technology, Industry and Economics, 2001.

[3] C. Chen, "The Investigation for the Establishment of Science Parks: The case of Taiwan", The Journal of American Academy of Business, Cambridge, vol. 8, no. 1, pp. 62-66, 2006.

[4] A. Zuckerman, "Compaq switches to pre-position inventory model”, World Trade, pp. 72-74, 2000.

[5] E. Barnes, J. Dai, S. Deng, D. Down, M. Goh, LH. Chuin and M. Sharafali, "On the strategy of supply hubs for cost reduction and responsiveness", White Paper On Electronics Supply Chain, Georgia Institute of Technology and National University of Singapore, 2000

[6] R. Gaonkar and N. Visvanadham, "Collaborative scheduling model for supply hub management", $3^{\text {rd }}$ Aegean International Conference on Design and Analysis of Manufacturing Systems, pp. 1-6, 2001.

[7] J. Shah and M. Goh, "Setting operating policies for supply hubs", International Journal of Production Economics, Vol. 100, No. 2, pp. 239-252, 2006

[8] J. Li, S. Ma, P. Guo, and Z. Zuo, "Analysis of Supply Chain Design with BOM Embedding Supply-Hub”, In: The proceeding of the WiCOM 2008, Shanghai, 2008.

[9] J. Li, N. Xiong, L. Sun, A. Yuan, J. Chen and M. Cao, "Supply Chain Design Model Based on Multi-Supply Hubs", 2009 International Conference on Computational Science and Engineering, vol. 1, pp. 449-454, 2009.

[10] S. Radas and SM. Shugan, "Seasonal Marketing and Timing New Product Introductions", Journal of Marketing Research, vol. 35, no 3, pp. 296-315, 1998.

[11] M. Chen and C. Lin, "Effects of Centralization on Expected Costs in a Multilocation Newsboy Problem", The Journal of the Operational Research Society, vol. 40, no. 6, pp. 597-602, 1989.

[12] G. Eppen, "Effects of Centralization on Expected Costs in a Multi-location Newsboy Problem", Management Science, vol. 25, no. 5, pp. 498-501, 1979. 